\title{
IDENTIFIKASI BAHAYA DAN PENILAIAN RISIKO PADA STASIUN SWITCHYARD DI PT.PJB UBJ O\&M PLTMG ARUN MENGGUNAKAN METODE HAZARD IDENTIFICATION, RISK ANALYSIS AND RISK CONTROL (HIRARC)
}

\author{
Cut Ita Erliana dan Abdul Azis \\ Jurusan Teknik Industri, Fakultas Teknik, Universitas Malikussaleh, Aceh, Indonesia \\ *Corresponding Author : cutitha@unimal.ac.id
}

\begin{abstract}
Abstrak - Penelitian ini dilakukan pada derah bertegangan tinggi, dimana masalah yang di hadapi akan mengganggu Gardu Induk (switchyard) 150 Kv di PT.PJB UBJ O\&M PLTMG arun. Bertujuan untuk mengetahui risiko bahaya perlu menjadi perhatian. serta untuk mengidentifikasi bahaya risiko. Dengan menggunakan metode hazard identification, risk analysis and risk control (hirarc) serta menggunakan pendekatan secara interview langsung ke pekerja. Dalam penelitian didapatkan 3 (tiga) aktivitas dimana masing-masing aktivitas terdiri dari 3(tiga),4(empat), dan 2(dua) proses sehingga memiliki total 9(sembilan) proses. Berdasarkan penilaian risiko maka risiko yang mungkin terjadi di switchyard Gardu Induk (switchyard) 150 kV di PT.PJB UBJ O\&M PLTMG arun yaitu 1 (satu) risiko Substansial Risk (9.1\%).,3 (tiga) risiko Moderate Risk (27,27\%), dan 7 (tujuh) risiko Trolerable Risk (63,63\%). Tingkatan risiko tersebut difungsikan untuk mendapatkan pengendalian pada semua risiko yang mungkin terjadi.
\end{abstract}

Kata Kunci : HIRARC, Keselamatan Kerja, Risiko, Swichyard

\section{Pendahuluan}

Listrik merupakan salah satu kebutuhan masyarakat yang sangat penting dan sebagai sumber daya ekonomis yang paling utama yang dibutuhkan dalam suatu kegiatan usaha. Dalam waktu yang akan datang kebutuhan listrik akan meningkat seiring dengan adanya peningkatan dan perkembangan baik dari jumlah penduduk, jumlah investasi yang semakin meningkat akan memunculkan berbagai industri-industri baru. Penggunaan listrik merupakan faktor yang penting dalam kehidupan masyarakat, baik pada sektor rumah tangga, penerangan, komunikasi,industri dan sebagainya [1] [2].

Dalam mengoperasikan pembangkit ini, terdapat banyak risiko yang terutama pada stasiun kerja Switchyard (Area Main Trafo) yang berkaitan dengan kesehatan dan keselamatan pekerja. Oleh karena itu dibutuhkan suatu metode untuk mengelola risiko tersebut. Pengelolaan risiko dapat dilakukan melalui manajemen risiko. Manajemen risiko dilakukan melalui beberapa tahap yaitu mengidentifikasi risiko, mengukur risiko dan merespon risiko tersebut. Pada penelitian ini manajemen risiko dilakukan melalui metode Hazard Identification, Risk Analysis and Risk Control (HIRARC). Pada HIRARC, risiko diidentifikasi berdasarkan lokasi dan pengukuran risiko dilakukan melalui nilai severity/ dampak dan likelihood/ kemungkinan terjadi [3] [4].

Mengidentifikasi bahaya bekerja pada daerah yang bertegangan yang mempunyai tingkat resiko yang cukup besar .Menghindari dan menanggulangi semua unsur yang berpotensial mengganggu jalannya proses produksi. Kemungkinan bahaya yang ditimbulkan biasanya disebabkan oleh faktor manusianya sendiri (unsafe action) dan bisa juga dari faktor lingkungan/kondisi yang tidak aman (unsafe condition). Memastikan pekerja agar 
bekerja dalam kondisi aman dan nyaman tanpa rasa cemas.

\section{Tinjauan Pustaka}

Prosedur K3 ini merupakan tahap atau proses suatu kegitan untuk menyelesaikan aktivitas atau metode (cara) langkah demi langkah secara pasti dalam pekerjaan dengan memperhatikan keselamatan, kesehatan, dan keamanan (K3). Adapun unsur-unsur yang terdapat dalam suatu organisasi atau instansi yaitu [5]:

1. Tenaga kerja.

Tenaga kerja adalah orang yang mampu melakukan pekerjaan, baik di dalam maupun diluar hubungan kerja, guna menghasilkan jasa atau barang untuk memenuhi kebutuhan masyarakat.

2. Pengusaha

Berikut adalah beberapa penjelasan mengenai pengusaha:

a. Orang persekutuan atau badan hukum yang menyalurkan suatu perusahaan milik sendiri.

b. Orang, persekutuan atau badan hukum yang secara berdiri sendiri menjelaskan perusahaan bukan miliknya.

c. Orang, persekutuan, atau badan hukum yang berada di Indonesia dalam huruf a dan b yang berkedudukan di luar wilayah Indonesia.

3. Perusahaan

Perusahaan adalah setiap bentuk badan usaha yang memperkerjakan tenaga kerja dengan tujuan mencari untung atau tidak, baik milik swasta maupun Negara.

4. Tempat kerja

Tempat kerja adalah setiap ruangan atau lapangan tertutup atau terbuka bergerak atau tetap di mana tenaga kerja bekerja, atau sering dimasuki tenaga kerja untuk keperluan suatu usaha dan di mana terdapat sumber atau sumber-sumber bahaya.

Pihak pengusaha atau perusahaan dapat melakukan prosedur bekerja dengan aman dan tertib menggunakan tahapan sebagai berikut:

1. Menetapkan standar K3

2. Menetapkan tata tertib yang harus dipatuhi

3. Menetapkan peraturan-peraturan

4. Mensosialisasikan peraturan dan perundangundangan k3 ini kepada seluruh tenaga kerja Memonitor pelaksanaan peraturan-peraturan.

\section{Bahaya}

Definisi bahaya menurut [6] adalah segala kondisi yang dapat merugikan baik cidera maupun kerugian lainnya. Berikut ini beberapa jenis atau macam bahaya yang sering dijumpai pada lingkungan kerja:

1. Bahaya fisik

Bahaya ini adalah bahaya yang dapat menyebabkan gangguan-gangguan kesehatan terhadap tenaga kerja yang terpapar, misalnya terpapar kebisingan intensitas tinggi, suhu ekstrim (panas dan dingin), intensitas penerangan kurang memadai, getaran, radiasi.

a. Radiasi

Radiasi adalah pancaran energi melalui suatu materi atau ruang dalam bentuk panas, partikel atau gelombang elektromagnetik/cahaya dari sumber radiasi. Ada beberapa sumber radiasi dalam lingkungan kerja, contohnya lampu penerangan, komputer, mesin, dan lain-lain

b. Kebisingan

Bising adalah campuran dari berbagai suara yang tidak dikehendaki ataupun yang merusak kesehatan, saat ini kebisingan merupakan salah satu penyebab penyakit lingkungan. Kebisingan dapat diartikan sebagai segala bunyi yang tidak dikehendaki yang dapat memberi pengaruh negatif terhadap kesehatan dan kesejahteraan seseorang maupun suatu populasi.

c. Penerangan

Penerangan yang kurang di lingkungan kerja bukan saja akan menambah beban kerja karena mengganggu pelaksanaan pekerjaan tetapi juga menimbulkan kesan kotor. Oleh karena itu penerangan dalam lingkungan kerja harus cukup untuk menimbulkan kesan yang higienis. Disamping itu cahaya yang cukup akan memungkinkan pekerja dapat melihat objek yang dikerjakan dengan jelas dan menghindarkan dari kesalahan kerja. Akibat dari kurangnya penerangan di lingkungan kerja akan menyebabkan kelelahan fisik dan mental bagi para karyawan atau pekerjanya.

d. Getaran

Getaran mempunyai parameter yang hampir sama dengan bising seperti: frekuensi, amplitudo, lama pajanan dan apakah sifat getaran terus menerus atau intermitten. Peralatan yang menimbulkan getaran juga dapat memberi efek negatif pada sistem saraf dan sistem musculoskeletal dengan mengurangi kekuatan cengkram dan sakit tulang belakang

2. Bahaya Kimia

Untuk bahaya ini bersumber dari bahan-bahan yang bersifat kimia dari bahan-bahan yang digunakan selama proses produksi. Potensi bahaya ini dapat memasuki atau mempengaruhi tubuh tenga kerja melalui inhalation (melalui pernafasan), ingestion (melalui mulut ke saluran pencernaan), skin contact (melalui kulit).

3. Bahaya Biologi

Yang termasuk kedalam kategori bahaya ini adalah virus, jamur, bakteri, tanaman, binatang yang dapat menginfeksi atau memberikan reaksi negatif kepada manusianya. 
4. Bahaya Fisiologis

Merupakan gangguan psikologis atau kejiwaan seseorang diakibatkan oleh adanya tekanan atau intervensi yang terjadi didalam lingkungan kerjanya. Sehingga dapat mengakibatkan gangguan terhadap fisik misalnya tekanan darah bahaya yang berasal atau yang disebabkan oleh penerapan ergonomi yang tidak baik atau tidak sesuai dengan norma-norma ergonomi yang berlaku.

\section{Bahaya Psiko-sosial}

Bahaya ini adalah bahaya yang berasal atau ditimbulkan oleh kondisi aspek-aspek psikologis ketenagakerjaan yang kurang baik atau kurang mendapatkan perhatian seperti penempatan tenaga kerja yang tidak sesuai dengan bakat, minat, kepribadian, motivasi, tempramen atau pendidikannya, sistem seleksi dan klasifikasi tenaga kerja yang tidak sesuai, kurangnya keterampilan tenaga kerja dalam melakukan pekerjaannya sebagai akibat kurangnya latihan kerja yang diperoleh, serta hubungan antara individu yang tidak harmoni dan tidak serasi dalam organisasi kerja. Kesemuanya tersebut akan menyebabkan terjadinya stress akibat kerja.

\section{Bahaya dari Proses Produksi}

Bahaya ini berasal atau ditimbulkan oleh beberapa kegiatan yang dilakukan dalam proses produksi, yang sangat bergantung dari: bahan dan peralatan yang dipakai, kegiatan serta jenis kegiatan yang dilakukan. Potensi bahaya keselamatan terdapat pada alat/mesin, serta bahan yang digunakan dalam proses produksi, seperti tertabrak, tertusuk, tertimpa, kerusakan mata akibat terkena debu feed additive, cutter, mesin kerusakan mata akibat terpercik garam, lecet akibat terkena part panas, dan kerusakan paruparu akibat terhirup debu las, luka bakar akibat kebocoran gas, terjepit part, semburan panas dari blow down otomatis, kebakaran, dan peledakan

\section{Resiko}

Definisi risiko menurut Kamus Besar Bahasa Indonesia (KBBI) adalah akibat yang kurang menyenangkan (merugikan, membahayakan) dari suatu perbuatan atau tindakan. Menurut [7] beberapa definisi risiko sebagaimana dapat kita lihat berikut ini:

1. Risk is the chance of loss (Risiko adalah kesempatan dari kerugian). Chance of loss biasanya dipergunakan untuk menunjukkan suatu keadaan dimana terdapat suatu keterbukaan (exposure) terhadap kerugian atau suatu kemungkinan kerugian. Sebaliknya jika disesuaikan dengan istilah yang dipakai dalam statistik, maka "chance" sering dipergunakan untuk menunjukkan tingkat probabilitas akan munculnya situasi tertentu.
2. Risk is the possibility of loss ( Risiko adalah kemungkinan kerugian). Istilah "possibility" berarti bahwa probabilitas suatu peristiwa berada diantara nol dan satu. Definisi ini barangkali sangat mendekati dengan pengertian risiko yang dipakai sehari-hari. Akan tetapi definisi ini agak longgar, tidak cocok dipakai dalam analisis secara kuantitatif. Risk is uncertainty (Risiko adalah ketidakpastian). Tampaknya ada kesepakatan bahwa risiko berhubungan dengan ketidakpastian (uncertainty) yaitu adanya risiko,karena adanya ketidakpastian

\section{Landasan Hukum Kesehatan dan Keselamatan Kerja}

Menurut [8] peraturan K3 di Indonesia telah ada sejak pemerintahan Hindia Belanda, peraturan K3 yang berlaku pada saat itu adalah Veiligheids Reglement. Setelah kemerdekaan dan diberlakukannya Undangundang Dasar 1945, maka beberapa peraturan termasuk peraturan keselamatan telah dicabut dan diganti. Peraturan yang mengatur tentang K3 adalah Undangundang Keselamatan Kerja No. 1 Tahun 1970.

Berikut ialah ketentuan-ketentuan penerapan K3 yang telah dijelaskan dalam Undang-undang Keselamatan Kerja No. 1 Tahun 1970 :

1. Tempat kerja yang menggunakan mesin, pesawat, perkakas.

2. Tempat kerja pembangunan, perbaikan, perawatan, pembersihan atau pembongkaran gedung.

3. Tempat usaha pertanian, perkebunan, pekerjaan hutan.

4. Pekerjaan usaha pertambangan dan pengelolahan emas, perak, loga,, serta biji logam lainnya, dan

5. Tempat pengangkutan, barang, binatang, dan manusia di daratan, melalui terowongan, permukaan air, dalam air dan di udara.

Sesuai dengan Undang-undang tersebut, maka tempat yang telah disebutkan harus dilakukan pelaksanaan prosedur Kesehatan dan Keselamatan Kerja. Dalam menjalankan pekerjaannya tenaga juga perlu payung hukum melinungi para pekerja dari tempat kerja. Untuk itu adapun dasar hukum yang menjadi payung para pekerja tentang $\mathrm{K} 3$ antara lain :

a) Undang-undang

- Undang-Undang Republik Indonesia No. 21 Tahun 2003 tentang pengesahan ILO Convetion No. 81 mengenai pengawasan ketenagakerjaan dalam industri dan perdangan,

- Undang-Undang Republik Indonesia No. 13 Tahun 2003 tentang ketenagakerjaan,

- Undang-Undang No. 1 Tahun 1970 tentang keselamatan kerja

b) Peraturan Pemerintah

- Peraturan Pemerintah No. 19 Tahun 1973 tentang pengaturan dan pengawasan keselamatan kerja di bidang pertambangan, 
- Peraturan Pemerintah No. 19 Tahun 1979 tentang keselamatan kerja pada pemurnian dan pengolahan minyak dan gas bumi.

c) Peraturan Menteri dan Keputusan Menteri

- Peraturan Menteri Tenaga Kerja dan Transmigrasi RI No. Per-01/MEN/1978 tentang keselamatan dan kesehatan kerja dalam pengangkutan dan penebangan kayu,

- Peraturan Menteri Tenaga Kerja dan Transmigrasi RI No. Per-03/MEN/1978 tentang persyaratan penunjukan dan wewenang, serta kewajiban pegawai pengawas keselamatan dan kesehatan kerja dan ahli kesehatan kerja,

- Peraturan Menteri Tenaga Kerja dan Transmigrasi RI No. Per-01/MEN/1980 tentang keselamatan dan kesehatan kerja pada kontruksi bangunan,

- Peraturan Menteri Tenaga Kerja dan Transmigrasi RI No. Per-03/MEN/1999 tentang syarat-syarat keselamatan dan kesehatan kerja lift untuk pengangkutan orang dan barang,

- Peraturan Menteri Tenaga Kerja dan Transmigrasi RI No. Per-03/MEN/1985 tentang keselamatan dan kesehatan kerja pemakaian abses.

- Peraturan Menteri Tenaga Kerja dan Transmigrasi RI No. Per-03/MEN/1986 tentang syarat-syarat keselamatan dan kesehatan kerja di tempat kerja yang mengelola pestisida.

- Peraturan Menteri Tenaga Kerja dan Transmigrasi RI Nomor 33 Tahun 2016 tentang Tata Cara Pengawasan Ketenagakerjaan

\section{Switchyard}

Switchyard adalah bagian dari gardu induk terbuka yang dijadikan sebagai tempat peletakan peralatan listrik berupa saklar - saklar pengaman, arrester dan pemutus Tegangan Tinggi. Pemahaman tentang switch yard, pada umumnya adalah :

a. Jika komponen utama gardu induk terpasang di area terbuka yang luas, maka disebut switchyard.

b. Jika komponen utama gardu induk terpasang di area terbatas (sempit) dan di dalam gedung, maka disebut switchgear.

C. Sebenarnya yang dimaksud switchgear, adalah peralatan yang ada di switchyard.

\section{Hazard Identification, Risk Assessment and Risk Control} HIRARC dimulai dari menentukan jenis kegiatan kerja yang kemudian diidentifikasikan sumber bahaya nya sehingga didapatkan risikonya. Kemudian akan dilakukan penilaian risiko dan pengendalian risiko untuk mengurangi paparan bahaya yang terdapat pada setiap jenis pekerjaan [4] [9].

1. Identifikasi Bahaya (Hazard Identification)
Identifikasi bahaya merupakan langkah awal dalam mengembangkan manajemen risiko K3. Identifikasi bahaya adalah upaya sistematis untuk mengetahui adanya bahaya dalam aktivitas organisasi. Identifikasi risiko merupakan landasan dari manajemen risiko, tanpa melakukan identifikasi bahaya tidak mungkin melakukan pengelolaan risiko dengan baik.

2. Penilaian Risiko (Risk Assessment)

Setelah semua risiko dapat teridentifikasi, dilakukan penilaian risiko melalui analisa dan evaluasi risiko.Analisa risiko dimaksudkan untuk menentukan besarnya suatu risiko dengan mempertimbangkan kemungkinan terjadinya dan besar akibat yang ditimbulkannya. Berdasarkan hasil analisa dapat ditentukan peringkat risiko sehingga dapat dilakuakan pemilahan risiko yang memiliki dampak besar terhadap perusahaan dan risiko yang ringan atau dapat diabaikan. Hasil analisa risiko dievaluasi dan dibandingkan dengan kriteria yang telah ditetapkan atau standard dan normal yang berlaku untuk menentukan apakah risiko tersebut dapat diterima atau tidak.

3. Pengendalian Risiko (Risk Control)

Kendali (control) terhadap bahaya dilingkungan kerja adalah tindakan- tindakan yang diambil untuk meminimalisir atau mengeliminasi risiko kecelakaan kerja melalui eliminasi, subsitusi, engineering control, warning system, administrative control, alat pelindung diri.

\section{Metodelogi Penelitian}

Dalam penelitian dibutuhkan beberapa data yang relevan yang akan digunakan dalam menyelesaikan permasalahan. Adapun jenis data yang dibutuhkan dalam penelitian yaitu data primer dan data sekunder.

1. Data Primer

Data primer didapatkan dengan Wawancara kepada pekerja, pihak engineering dan pihak maintenance

2. Data Sekunder

1. Layout dari stasiun switchyard

2. SOPperawatan peralatan stasiunswitchyard

Mengingat perlunya berbagai macam data yang dilakukan dalam penelitian ini, maka penulis menggunakan beberapa teknik pengumpulan data, yaitu:

1. Wawancara (interview)

Merupakan salah satu cara untuk mendapatakan data maupun informasi melalui tanya jawab secara langsung kepada pihak perusahaan. Pertanyaan yang diajukan secara spesifik dan hanya membuat poinpoin penting masalah yang ingin diketahui oleh penulis.

2. Pengamatan (observasi)

Pengamatan atau peninjauan langsung terhadap objek penelitian dengan cara melakukan pengamatan 
serta pencatatan secara langsung pada obyek yang diteliti di PT. PJB UBJ O\&M PLTMG ARUN. seperti proses kerja pada pelepasan dan penormalan tegangan.

\section{Hasil Penelitian dan Pembahasan}

1. Identifikasi bahaya

adalah upaya sistematis untuk mengetahui adanya bahaya dalam aktivitas organisasi. Identifikasi risiko merupakan landasan dari manajemen risiko, tanpa melakukan identifikasi bahaya tidak mungkin melakukan pengelolaan risiko dengan baik. Berikut adalah nilai tingkat kemungkinan terjadinya suatu hal, dapat kita lihat pada Tabel 1 berikut ini:

Tabel 1 Tingkat Kemungkinan

\begin{tabular}{|c|c|l|}
\hline Likehood/Probability & Rating & Deskripsi \\
\hline Frequent & 5 & $\begin{array}{l}\text { Selalu } \\
\text { Terjadi }\end{array}$ \\
\hline Probable & 4 & $\begin{array}{l}\text { Sering } \\
\text { Terjadi }\end{array}$ \\
\hline Occasional & 3 & $\begin{array}{l}\text { Kadang- } \\
\text { kadang } \\
\text { Terjadi }\end{array}$ \\
\hline Unlikely & 2 & $\begin{array}{l}\text { Mungkin } \\
\text { Dapat } \\
\text { Terjadi }\end{array}$ \\
\hline Improbable & 1 & $\begin{array}{l}\text { Tidak } \\
\text { Terjadi }\end{array}$ \\
\hline
\end{tabular}

Tingkat kemungkinan bahaya yang diidentifikasi bahaya risiko melalui analisa dan evaluasi bahaya risiko yang dimaksudkan untuk menentukan besarnya risiko dengan mempertimbangkan kemungkinan terjadi dan besar akibat yang ditimbulkan.

Proses HIRARC pada sebuah perusahaan adalah dengan Mengidentifikasi semua kegiatan baik yang rutin maupun tidak rutin (abnormal) di unit kerja, atau kegiatan yang dapat menyebabkan keadaan darurat. kemudian mengidentifikasi sumber bahaya yang berhubungan dengan kegiatan yang diidentifikasi. Untuk lebih jelasnya mengenai identifikasi kegiatan dan risiko pekerjaan dapat dilihat pada Tabel 2 berikut:

Tabel 2 Identifikasi Bahaya pada Stasiun Swichyard

\begin{tabular}{|l|c|}
\hline Kegiatan Pekerjaan & $\begin{array}{r}\text { Risiko dari } \\
\text { Pekerjaan }\end{array}$ \\
\hline A. Pelepasan tegangan Switchyard 150 kV \\
\hline
\end{tabular}

\begin{tabular}{|c|c|c|}
\hline & $\begin{array}{l}\text { 1. Saat pengaktifan } \\
\text { PMS ground } \\
\text { pekerjaan } \\
\text { pengecekkan } \\
\text { grounding dan } \\
\text { pengait/tuas } \\
\text { penghantar }\end{array}$ & $\begin{array}{l}\text { Rrisikonya kecil } \\
\text { (low) kkarena } \\
\text { dampak yang } \\
\text { dditimbulkan } \\
\text { titidak sampai } \\
\text { melukai }\end{array}$ \\
\hline & $\begin{array}{l}\text { 2. Saat melepas } \\
\text { penghantarnya } \\
\text { (connector) pada } \\
\text { PMS } 204\end{array}$ & $\begin{array}{l}\text { Ttersengat arus } \\
\text { listrik }\end{array}$ \\
\hline & $\begin{array}{l}\text { 3. Saat melepas } \\
\text { penghantarnya } \\
\text { (connector) pada } \\
\text { PMS 891LG1 }\end{array}$ & $\begin{array}{l}\text { Tterjadinya } \\
\text { ledakan ddan } \\
\text { tersengat listrik }\end{array}$ \\
\hline B. & \multicolumn{2}{|c|}{ Perawatan Peralatan Switchyard 150 kV } \\
\hline & $\begin{array}{l}\text { 1. pemutusan saklar } \\
\text { pengoperasian } \\
\text { (kondisi lock) }\end{array}$ & $\begin{array}{l}\text { Risikonya kecil } \\
\text { (low) karena } \\
\text { dampak yang } \\
\text { ditimbulkan tidak } \\
\text { sampai melukai. }\end{array}$ \\
\hline & $\begin{array}{l}\text { 2. pengecekan } \\
\text { tahanan isolasi dan } \\
\text { grounding } \\
\text { peralatan }\end{array}$ & $\begin{array}{l}\text { Risikonya kecil } \\
\text { (low) karena } \\
\text { dampak yang } \\
\text { ditimbulkan tidak } \\
\text { sampai melukai. }\end{array}$ \\
\hline & $\begin{array}{l}\text { 3. pengisian gasSulfur } \\
\text { Hexafluoride (SF- } \\
\text { 6)dan setting ulang } \\
\text { peralatan sesuai } \\
\text { dengan nameplate } \\
\text { yang tertera di body } \\
\text { panel }\end{array}$ & $\begin{array}{l}\text { Gangguan } \\
\text { pernafasan } \\
\text {,iritasi mata, } \\
\text { iritasi kulit. }\end{array}$ \\
\hline & \multirow{3}{*}{$\begin{array}{l}\text { 4. pembersihan } \\
\text { isolator kabel } \\
\text { line/busbar berada } \\
\text { di ketinggian }\end{array}$} & $\begin{array}{l}\text { Jatuh karena } \\
\text { berada di } \\
\text { ketinggian. }\end{array}$ \\
\hline & & $\begin{array}{l}\text { Iritasi mata } \\
\text { akibat debu }\end{array}$ \\
\hline & & Terpapar panas \\
\hline C. & \multicolumn{2}{|c|}{ Penormalan tegangan Switchyard $150 \mathrm{Kv}$} \\
\hline & $\begin{array}{l}\text { 1. perawatan dari } \\
\text { kabel pentanahan }\end{array}$ & $\begin{array}{l}\text { Tersengat listrik } \\
\text { arus DC } \\
\text { peralatan (arus } \\
\text { bocor) }\end{array}$ \\
\hline & \multirow[t]{2}{*}{ 2. pemasangan pengait } & $\begin{array}{l}\text { Tangan terjepit } \\
\text { jika pemasangan } \\
\text { pengaitnya tidak } \\
\text { tepat (luka } \\
\text { memar) }\end{array}$ \\
\hline & & $\begin{array}{l}\text { terjatuh dan } \\
\text { tersengat listrik } \\
\text { arus AC dari } \\
\text { kabel line }\end{array}$ \\
\hline
\end{tabular}

\section{Penilaian Risiko}


Setelah semua risiko dapat teridentifikasi, dilakukan penilaian risiko melalui analisa dan evaluasi risiko.Analisa risiko dimaksudkan untuk menentukan besarnya suatu risiko dengan mempertimbangkan kemungkinan terjadinya dan besar akibat yang ditimbulkannya. Penilaian risiko (Risk Assessment) mencakup dua tahapan proses yaitu menganalisa risiko (Risk Analysis) dan mengevaluasi risiko (Risk Evaluation). Kedua tahapan ini sangat penting karena akan menentukan langkah dan strategi pengendalian risiko.

Tabel 3 Skala Tingkatan Risiko

\begin{tabular}{|c|l|l|}
\hline $\begin{array}{c}\text { Risk } \\
\text { Rank }\end{array}$ & \multicolumn{1}{|c|}{ Kategori } & \multicolumn{1}{|c|}{ Tindakan } \\
\hline $\begin{array}{c}17- \\
25\end{array}$ & Extreme High risk & $\begin{array}{l}\text { Penghentian aktifitas } \\
\text { sampai tingkat risiko } \\
\text { dikurangi }\end{array}$ \\
\hline $10-$ & High risk & Memerlukan penanganan \\
16 & Medium risk & Memerlukan perhatian \\
\hline $5-9$ & Low risk & Lakukan seperti biasa \\
\hline $1-4$ & & \\
\hline
\end{tabular}

Hasil Penilaian berdasarkan risk assessment diketahui nilai risiko dan tindakan yang harus diambil dari seluruh potensi bahaya yaitu, risiko ringan (low risk), risiko sedang (moderate risk), risiko tinggi (high risk) dan risiko sangat tinggi (extrim risk). Dalam pengkategorian tingkat risiko terdapat perhitungan persentase kategori sebagai berikut:

\%Kategori = $\underline{\text { Jumlah Risiko Pekerjaan tiap kategori }}$ $100 \% \ldots \times 1 \quad$ Jumlah seluruh pekerjaan

tempat kerja terdapat sumber bahaya yang beraneka ragam mulai dari kapsitas bahaya yang rendah hingga bahaya yang tinggi. Jenis kategori hazard adalah bahaya fisik, bahaya kimia, bahaya mekanik, bahaya elektrik, bahaya ergonomi, bahaya kebiasaan, bahaya lingkungan, bahaya biologi, dan bahaya psikologi.

Tabel 4.Penilaian Risiko Pekerjaan

\begin{tabular}{|c|l|c|c|c|}
\hline No & \multicolumn{1}{|c|}{ Risiko } & $\begin{array}{c}\text { Tingkat } \\
\text { Kemungkinan }\end{array}$ & $\begin{array}{c}\text { Tingkat } \\
\text { Keparahan }\end{array}$ & $\begin{array}{c}\text { Total } \\
\text { Penilaian }\end{array}$ \\
\hline 1 & $\begin{array}{l}\text { Tersengat } \\
\text { arus listrik }\end{array}$ & 3 & 2 & 6 \\
\hline 2 & $\begin{array}{l}\text { Terjadinya } \\
\text { ledakan }\end{array}$ & 3 & 1 & 3 \\
\hline 3 & Tergelincir & 3 & 3 & 9 \\
\hline 4 & $\begin{array}{l}\text { Luka bakar } \\
\text { ringan }\end{array}$ & 3 & 2 & 6 \\
\hline 5 & Iritasi mata & 3 & 1 & 3 \\
\hline 6 & $\begin{array}{l}\text { Gangguan } \\
\text { pernapasan }\end{array}$ & 4 & 2 & 8 \\
\hline
\end{tabular}

\begin{tabular}{|l|l|l|l|l|}
\hline 7 & $\begin{array}{l}\text { Tangan } \\
\text { terjepit }\end{array}$ & 3 & 3 & 9 \\
\hline
\end{tabular}

Berdasarkan data hasil pengamatan, maka dapat dilakukan penilaian terhadap risiko berdasarkan nilai tingkat kemungkinan dan juga tingkat keparahan dari bahaya risiko pekerjaan yang dilakukan. Dapat dilihat total penilaian risiko dari semua kegiatan yang dilakukan. Untuk lebih jelasnya maka akan diuraikan sebagai berikut:

1. Tersengat arus listrik

a. Tingkat Kemungkinan

Saat pengaktifan PMS ground pekerjaan pengecekkan grounding dan pengait/tuas penghantar terkadang tersengat arus bocor. Oleh sebab itu, nilai tingkat kemungkinannya adalah 3 (kadang-kadang terjadi).

b. Tingkat Keparahan

Akibat tersengat arus bocor maka dapat menimpa pekerja yang mengakibatkan luka bakar dan harus mendapatkan penanganan P3K dan biaya finansial. maka nilai tingkat keparahannya adalah 2 .

Dari hasil penilaian diatas maka didapatkan nilai risiko tertimpa adalah 6 .

2. Terjadinya ledakan

a. Tingkat Kemungkinan

Pada saat pekerja pekerja Saat melepas penghantarnya (connector) pada PMS 891LG1 dapat berakibat terjadinya ledakan pada trafo utama . Oleh sebab itu, nilai tingkat kemungkinannya adalah 3 (kadang-kadang terjadi).

b. Tingkat Keparahan

Akibat dari terjadinya ledakan menimbulkan cidera serius ataupun mengganggu proses kerja, dan dapat mengakibatkan kematian Maka nilai tingkat keparahannya adalah 1.

Dari hasil penilaian diatas maka didapatkan nilai terjadi ledakan adalah 3.

3. Tergelincir

a. Tingkat Kemungkinan

Pada saat pembersihan isolator kabel line/busbar berada di ketinggian terkadang sepatu split dan tergelincir. Oleh sebab itu, nilai tingkat kemungkinannya adalah 3 (kadang-kadang).

b. Tingkat Keparahan

Akibat dari tergelincir di area pembersihan isolator kabel line/busbar berada di ketinggian yang mengakibatkan keseleo dan harus memerlukan perawatan medis dan terganggunya pekerja,. Maka nilai tingkat keparahannya adalah 3.

Dari hasil penilaian diatas maka didapatkan nilai risiko tertimpa adalah 9. 
4. Luka Bakar ringan

a. Tingkat Kemungkinan

Karena Saat melepas penghantarnya (connector) pada PMS 204 mungkin terjadi arus bocor dan mengakibatkan luka bakar. Oleh sebab itu, nilai tingkat kemungkinannya adalah 3 (kadang-kadang terjadi).

b. Tingkat Keparahan

Luka bakar ringan biasanya akan membutuhkan penanganan kotak P3K langsung Maka nilai tingkat kemungkinannya adalah 2.

Dari hasil penilaian didapatkan nilai risiko luka bakar ringan adalah 6 .

5. Iritasi Mata

a. Tingkat Kemungkinan

Pada saat membersihkan abu pada pembersihan isolator kabel line. Kegiatan tersebut dilakukan berulang kali sehingga dapat mengakibatkan iritasi pada mata. Hal ini kadang-kadang masih dapat terjadi. Maka nilai tingkat kemungkinannya adalah 3 (kadangkadang dapat terjadi).

b. Tingkat Keparahan

Iritasi mata biasanya tidak menimbulkan cidera yang serius, tidak mengganggu proses pekerjaan, Maka nilai tingkat keparahan adalah 1.

Dari hasil penilaian didapatkan nilai risiko iritasi mata adalah 3.

6. Gangguan Pernapasan

a. Tingkat Kemungkinan

Pada saat pengisian gasSulfur Hexafluoride (SF-6)dan setting ulang peralatan sesuai dengan nameplate yang terteradi body panel. Hal tersebut sering terjadi karena pekerja tidak menggunakan masker sesuai dengan standar sesuai pekerjaan. Oleh sebab itu maka nilai tingkat kemungkinannya adalah 4 (sering terjadi).

b. Tingkat Keparahan

Akibat dari gangguan pernapasan biasanya pekerja akan membutuhkan penanganan $\mathrm{P} 3 \mathrm{~K}$, Maka nilai tingkat keparahannya adalah 2.

Dari hasil penilaian didapatkan nilai risiko gangguan pernafasan adalah 8 .

7. Tangan terjepit

a. Tingkat Kemungkinan

Pada saat pemasangan pengait Tangan terjepit jika pemasangan pengaitnya tidak tepat (luka memar) Maka nilai kemungkinannya adalah 3 (kadang-kadang dapat terjadi).

b. Tingkat Keparahan

Akibat dari Tangan terjepit jika pemasangan pengaitnya tidak tepat (luka memar). Maka nilai tingkat keparahannya adalah 3 , dari hasil penilaian didapatkan nilai risiko gangguan pernafasan adalah 9.

\section{Tabel 6 Matrix risiko}

Parameter yang digunakan untuk melakukan penilaian resiko adalah likelihood dan severity. Likelihood adalah probabilitas terjadinya kecelakaan kerja. Parameter pengukuran likelihood yang digunakan dalam penelitian ini adalah seberapa sering terjadinya kegiatan yang dapat memicu kecelakaan

\begin{tabular}{|c|c|c|c|c|}
\hline \multirow[b]{2}{*}{$\begin{array}{c}\text { Likelihoo } \\
d\end{array}$} & \multicolumn{4}{|c|}{ Severity } \\
\hline & $\begin{array}{c}\text { Insignifi } \\
\text { cant } \\
\text { (1) }\end{array}$ & $\begin{array}{l}\text { Slightly } \\
\text { Harmful } \\
\text { (3) }\end{array}$ & $\begin{array}{l}\text { Harmful } \\
\text { (5) }\end{array}$ & $\begin{array}{c}\text { Extremel } \\
y \\
\text { Harmful } \\
\text { (10) }\end{array}$ \\
\hline $\begin{array}{c}\text { Very } \\
\text { unlikely } \\
\text { (1) }\end{array}$ & Trivial & Trivial & $\begin{array}{c}\text { Tolerabl } \\
e\end{array}$ & $\begin{array}{c}\text { Moderat } \\
e\end{array}$ \\
\hline $\begin{array}{c}\text { Unlikely } \\
\text { (3) }\end{array}$ & Trivial & $\begin{array}{c}\text { Tolerabl } \\
e\end{array}$ & $\begin{array}{c}\text { Moderat } \\
e\end{array}$ & $\begin{array}{c}\text { Substant } \\
\text { ial }\end{array}$ \\
\hline $\begin{array}{l}\text { Likely } \\
\text { (5) }\end{array}$ & $\frac{\text { Tolerab }}{\text { le }}$ & $\begin{array}{c}\text { Moderat } \\
e\end{array}$ & $\frac{\text { Substant }}{\text { ial }}$ & $\frac{\text { Intolerab }}{\text { le }}$ \\
\hline $\begin{array}{l}\text { Very } \\
\text { likely } \\
(10)\end{array}$ & $\begin{array}{c}\text { Modera } \\
\text { te }\end{array}$ & $\begin{array}{c}\text { Substant } \\
\text { ial }\end{array}$ & $\begin{array}{c}\text { Intolera } \\
\text { ble }\end{array}$ & $\begin{array}{c}\text { Intolerab } \\
\text { le }\end{array}$ \\
\hline
\end{tabular}

kerja. Risk rating menggambarkan seberapa besar dampak dari potensi bahaya yang diidentifikasi.

Setelah melakukan penilaian terhadap risiko pekerjaan pada stasiun Switchyard, pekerjaanpekerjaan tersebut dapat dikategorikan dalam skala tingkat risiko. Pada umumnya skala tingkat risiko diperoleh dari hasil kali antara probabilitas terjadinya kecelakaan dengan tingkat keparahan. Hasilnya dapat dilihat pada Tabel 4.5 diatas. Kemudian hasil perkalian tersebut disesuaikan dengan tabel skala tingkat risiko. Dari hasil tabel tersebut dapat dilihat pekerjaanpekerjaan yang telah digolongkan kedalam skala tingkat risikonya. Berikut ini adalah tabel Pengkategorian risiko pekerjaan yang ada pada pekerjaan untuk perawatan switchyard $150 \mathrm{kv}$ dapat kita lihat pada tabel 7 berikut ini:

Tabel 7 Pengkategorian Risiko Pekerjaan

\begin{tabular}{|l|l|}
\hline Klasifikasi Risiko & Risiko Pekerjaan \\
\hline & $\begin{array}{l}\text { a. } \\
\text { b. }\end{array}$ \\
& bangguan pernapasan \\
Trolerable Risk & c. Jaterial yang diangkat mel \\
& d. Tersand ketinggian \\
& e. Iritasi mata \\
& f. Terpapar panas \\
& g. Tergores tools
\end{tabular}




\begin{tabular}{|l|l|}
\hline Moderate Risk & $\begin{array}{l}\text { a. Jari tangan terjepit } \\
\text { b. Tersengat arus listrik } \\
\text { c. Sling terputus }\end{array}$ \\
\hline Substansial Risk & Terbakar sewaktu pemutusan PN \\
& \\
\hline
\end{tabular}

Kategori resiko yang dominan dari nilai resiko pada potensi bahaya kerja di area stasiun Switchyard adalah $\mathrm{L}$ atau low risk yang berarti kendalikan dengan prosedur rutin. Berdasarkan hasil perhitungan yang dilakukan jika dikonversikan kedalam bentuk skala angka didapatkan presentasi risiko dari kegiatan pekerjaan untuk perawatan switchyard $r$ yaitu sebagai berikut:

1. \% Trolerable Risk

Berikut adalah perhitungan dari persentase low risk:

$\%$ Trolerable Risk $=\frac{7}{11} \times 100 \%=63,63 \%$

2. \% Moderate Risk

Berikut adalah perhitungan dari persentase medium risk:

$\%$ Moderate Risk $=\frac{3}{11} \times 100 \%=27,27 \%$

7

3. \% Substansial Risk

Berikut adalah perhitungan dari persentase high risk:

$\%$ Substansial Risk $=\frac{1}{11} \times 100 \%=9,1 \%$

7

\section{Pengendalian risiko}

Berdasarkan pada hasil perhitungan sebelumnya maka untuk menghindari terjadinya kejadian yang tidak diinginkan, diperlukan adanya suatu pengendalian risiko terhadap risiko pekerjaan.

\section{Kesimpulan}

1. Dari hasil penelitian dan pembahasan yang telah dilakukan, maka dapat disimpulkan Jenis bahaya pekerjaan pada daerah bertegangan (switchyard 150 kv) di PT PJB UBJ O\&M PLTMG ARUN Dari hasil observasi penelitian berupa dokumen yang dilakukan peneliti serta hasil wawancara dengan informan, maka didapatkan sumber bahaya yaitu; Tersengat arus listrik, Terjadinya ledakan, Tergelincir, Luka bakar ringan, Iritasi mata, Gangguan pernapasan, Tangan terjepit.

2. Penilaian Risiko keselamatan dan kesehatan kerja berdasarkan sumber bahaya pada pekerjaan daerah bertegangan (switchyard $150 \mathrm{kv}$ ) memiliki tingkatan risiko mulai dari skor terendah hingga tinggi yaitu
Trolerable Risk, Moderate Risk, dan Substansial Risk. Dimana, 7 jenis risiko pekerjaan termasuk pada kategori Trolerable Risk (63,63\%), 3 risiko pekerjaan termasuk pada kategori Moderate Risk (27,27\%),dan 1 risiko pekerjaan termasuk pada kategori Substansial Risk(9.1\%)

3. Upaya yang dilakukan untuk mengurangi atau mengendalikan tingkat risiko agar menjadi rendah sesuai dengan hirarki risiko serta peraturan perundang undangan Dengan menggunakan metode (HIRARC) diketahui bahwa dampak risiko yang paling besar yaitu dapat menyebabkan patah tulang dan tersengat arus listrik sehingga dapat menyebabkan lumpuh dan kematian (substanstial, score 30). Dampak risiko yang sedang yaitu dapat menyebabkan luka lebam/memar karena terjatuh dan terjadi benturan dengan penghantar/connector (moderatel, score 15). Dampak risiko yang ringan yaitu tersengat listrik dari peralatan dan terbentur penghantar/connector namun tidak menyebabkan luka lebam/ memar (trivial, score 3).

4. Maka tindakan pengendalian/penurunan risiko dapat dilakukan dengan penggunaan APD seperti safety shoes dan sarung tangan kulit, serta APAR, Rambu K3 dan pembatasan akses pada area ini, serta operator perlu diberikan pembinaan keselamatan dan kesehatan kerja, diberikan pengujian kesehatan atau proses evakuasi jika terjadi kecelakaan serta pengendalian teknis agar bahaya bisa dihindari. karyawan harus melakukan pengujian kesehatan setiap tahun sesuai ketentuan perusahaan, Pihak yang berwenang harus selalu melakukan monitoring lingkungan kerja tersebut, serta larangan makan dan minum di tempat kerja. Penetapan sistem permit to work serta melalukan sosialisasi dan pelatihan tanggap darurat.

\section{Daftar Pustaka}

[1] Y. D. Arfita, Antonov, S. Yuliananda, G. Sarya, and R. R. Hastijanti, "Pemanfaatan energi surya sebagai suplai cadangan pada laboratorium elektro dasar di institut teknologi padang," J. Pengabdi. LPPM Untag Surabaya, 2015.

[2] I. A. Koagouw, W. Supit, and J. F. Rumampuk, "PENGARUH KEBISINGAN MESIN LAS DISEL LISTRIK TERHADAP FUNGSI PENDENGARAN PADA PEKERJA BENGKEL LAS DI KECAMATAN MAPANGET KOTA MANADO," J. e-Biomedik, 2013, doi: 10.35790/ebm.1.1.2013.3679.

[3] A. M. Saedi, J. J. Thambirajah, and A. Pariatamby, "A HIRARC model for safety and risk evaluation at a hydroelectric power generation plant," Saf. Sci., 2014, doi: 10.1016/j.ssci.2014.05.013.

[4] P. Pertiwi, Y. Nurhantari, and S. Budihardjo, "Hazard identification, risk assesment and risk 
control serta penerapan risk mapping pada rumah sakit hewan Prof. Soeparwi Universitas Gadjah Mada," Ber. Kedokt. Masy., 2019, doi: 10.22146/bkm.42376.

[5] D. P. Restuputri, "Analisis Kecelakaan Kerja Dengan Menggunakan Metode Hazard and Operability Study ( Hazop )," J. Ilm. Tek. Ind., 2015.

[6] D. W., "Sistem Manajemen Keselamatan dan Kesehatan Kerja," Permenaker Nomor 5, 2006.

[7] C. I. Erliana and R. Rajagukguk, "ANALISA POSTUR KERJA DENGAN MENGGUNAKAN METODE RAPPID UPPER LIMB ASSESSMENT ( RULA ) PADA PEKERJA BAGIAN MOTHER PLANT DEPARTEMEN NURSERY," in Seminar Nasional Teknik Industri [SNTI2017], 2017.

[8] A. Amri, C. I. Erliana, and R. A. F. Lubis, "ANALISIS PENGARUH KEBISINGAN TERHADAP KELELAHAN KARYAWAN DI BAGIAN OPERASI-1 PT. PUPUK ISKANDAR MUDA, KRUENG GEUKUH, ACEH UTARA," Ind. Eng. J., 2019.

[9] A. Primasari, H. Denny, and E. Ekawati, "PENERAPAN HAZARD IDENTIFICATION RISK ASSESSMENT AND RISK CONTROL (HIRARC) SEBAGAI PENGENDALIAN POTENSI KECELAKAAN KERJA DI BAGIAN PRODUKSI BODY BUS PT. $X$ MAGELANG," J. Kesehat. Masy., 2016. 